\title{
Outcomes of Simultaneous Resections and Classical Strategy for Synchronous Colorectal Liver Metastases in Sweden: A Nationwide Study with Special Reference to Major Liver Resections
}

\author{
Valentinus T. Valdimarsson ${ }^{1} \cdot$ Ingvar Syk $^{2} \cdot$ Gert Lindell $^{1} \cdot$ Per Sandström $^{3,4} \cdot$ Bengt Isaksson $^{5}$ • \\ Magnus Rizell ${ }^{6} \cdot$ Agneta Norén $^{5} \cdot$ Bjarne Ardnor $^{7} \cdot$ Christian Sturesson $^{8}$
}

Published online: 17 March 2020

(C) The Author(s) 2020

\begin{abstract}
Background About $20 \%$ of patients with colorectal cancer have liver metastases at the time of diagnosis, and surgical resection offers a chance for cure. The aim of the present study was to compare outcomes for patients that underwent simultaneous resection to those that underwent a staged procedure with the bowel-first (classical) strategy by using information from two national registries in Sweden.

Methods In this prospectively registered cohort study, we analyzed clinical, pathological, and survival outcomes for patients operated in the period 2008-2015 and compared the two strategies.

Results In total, 537 patients constituted the study cohort, where 160 were treated with the simultaneous strategy and 377 with the classical strategy. Patients managed with the simultaneous strategy had less often rectal primary tumors ( $22 \%$ vs. $31 \%, p=0.046)$ and underwent to a lesser extent a major liver resection $(16 \%$ vs. $41 \%, p<0.001)$, but had a shorter total length of stay ( 11 vs. 15 days, $p<0.001)$ and more complications $(52 \%$ vs. $36 \%, p<0.001)$. No significant 5 -year overall survival $(p=0.110)$ difference was detected. Twenty-five patients had a major liver resection in the simultaneous strategy group and 155 in the classical strategy group without difference in 5-year overall survival $(p=0.198)$.

Conclusion Simultaneous resection of the colorectal primary cancer and liver metastases can possibly have more complications, with no difference in overall survival compared to the classical strategy.
\end{abstract}

Christian Sturesson

christian.sturesson@sll.se

1 Department of Clinical Sciences Lund, Surgery, Skane University Hospital, Lund University, Lund, Sweden

2 Department of Clinical Sciences Malmö, Surgery, Skane University Hospital, Lund University, Malmö, Sweden

3 Department of Surgery, Linköping University, Linköping, Sweden

4 Department of Clinical and Experimental Medicine, Linköping University, Linköping, Sweden

5 Department of Surgical Sciences, Uppsala University, Uppsala, Sweden
6 Department of Transplantation and Liver Surgery, Sahlgrenska Academy, University of Gothenburg, Gothenburg, Sweden

7 Department of Surgery, Umeå University Hospital, Umeå, Sweden

8 Division of Surgery, Department of Clinical Science, Intervention and Technology (CLINTEC), Karolinska Institutet, Karolinska University Hospital, 14186 Stockholm, Sweden 


\section{Introduction}

Cancer from the colon or rectum is the third most common malignancy worldwide $[1,2]$. At diagnosis, $15-20 \%$ of patients present with synchronous liver metastases (sCRLM) [3-5]. Although possible for only a minority of patients, resection of all tumors offers a chance for cure. Different strategies exist for surgical treatment. The primary tumor can be resected first, and the liver metastases can be addressed at a later stage, with or without chemotherapy in the interval between operations, the socalled classical strategy. Alternatively, the surgical treatment order is reversed, where the liver metastases are resected before the primary, the liver-first strategy [6]. The third option includes resection of both the primary colorectal cancer and the metastases in the liver during the same operation, the simultaneous strategy.

The simultaneous strategy seems to be safe when compared to the other strategies and has been shown to reduce the total length of hospital stay. This strategy is increasingly applied when a patient has a limited liver tumor disease burden, and the primary tumor resection is assumed uncomplicated. The indication for proposing the simultaneous strategy is still evolving. No overall survival difference has been observed between the above strategies, although most studies only analyze patients that complete the entire surgical strategy without intention-to-treat analysis [7-10]. No randomized controlled investigation exists to date.

The treatment impact on patient outcome has previously been analyzed only from retrospective data collected from single or a few centers. No nationwide study has previously been published on simultaneous resections, and little data are available for patients that have undergone major resections. The aim of this study was to evaluate and compare a simultaneous strategy to a classical strategy for patients diagnosed with sCRLM, based on information from two population registries from Sweden with a focus on patients undergoing major liver resections.

\section{Material and methods}

National registries for colorectal (SCRCR) and liver and bile duct (Sweliv) cancers were used to identify patients diagnosed with colorectal cancer between 2008 and 2015. Both registries have prospective registration of data, where SCRCR includes $94-98 \%$ of all patients diagnosed with colorectal cancer in Sweden [11], and Sweliv includes patients with primary liver cancer and bile duct cancer in addition to all surgical treatments for a primary and metastatic cancer in the liver. Sweliv includes $96 \%$ of all patients with cancers in the liver or bile ducts in Sweden [12].

Patients with colorectal cancer and liver metastases were identified from the registries at the time of diagnosis and are defined as having sCRLM. Patients that underwent an acute operation for their primary were excluded. A cohort of patients only undergoing elective colorectal resection and no liver resection was analyzed separately. Patients undergoing colorectal resection within 6 months from the diagnosis, and both primary tumor and liver resection within 12 months from diagnosis, constituted the patient cohort in the present study. Patients with sCRLM that only underwent liver resection and those that underwent the liver-first strategy were identified separately, as previously published [13]. A comparison was made between patients that had undergone the simultaneous strategy and those that underwent the classical strategy. A liver resection of three or more Couinaud's segments was classified as a major resection. Morbidity was registered as 30-day complications demanding treatment. A more detailed specification of morbidity was not available in the registries. In the staged resection group, a complication in either procedure was considered a complication for the procedures combined. An R0 surgical margin is defined as a microscopic surgical-free specimen margin. Tumor burden score (TBS) in the liver was calculated as $\mathrm{TBS}^{2}=d^{2}+n^{2}$, where $d=$ largest liver tumor diameter $(\mathrm{cm})$ and $n=$ number of liver lesions [13].

\section{Statistics}

Results were showed as numbers and percentages when categorical variables and Fisher's exact test were used to compare groups. For continuous variables, results are presented as median with interquartile ranges (IQRs), and Mann-Whitney $U$ test was used to compare groups. Survival from the time of diagnosis was estimated using Kaplan-Meier analysis. Patient and tumor characteristics effect on survival was investigated using multi- and univariate Cox proportional hazards $(\mathrm{PH})$ models. A $p$ value of less than 0.05 was considered statistically significant. The statistical software used was R (R Core Team (2018). $\mathrm{R}$ Foundation for Statistical Computing, Vienna, Austria).

\section{Results}

In the SCRCR, 39016 patients with colorectal cancer were identified, of which 6105 (16\%) patients had liver metastases at the time of diagnosis. Of those, a total of 1571 (26\%) underwent elective surgery of the primary tumor. Seven-hundred and eighty-eight patients underwent colorectal resection only and no liver resection. A total of 783 
patients underwent both colorectal and liver resections, constituting $2 \%$ of the initially identified patient group diagnosed with colorectal cancer. Of the 783 patients, 377 underwent a classical strategy, and 160 underwent a simultaneous strategy, as shown in Fig. 1. Patients' characteristics for the classical and simultaneous strategy are shown in Table 1. One patient died within 30 days of the resection in the simultaneous groups, but none in the classical strategy group. The number resected with the simultaneous strategy increased in the first 3 years of the study period from six patients per year to 30 per year, with a median of $26(18-30)$ patients resected per year. Eighteen patients $(5 \%)$ underwent a laparoscopic liver procedure in the classical strategy group and $4(3 \%)$ in the simultaneous strategy group $(p=0.340)$.

Twenty-five and 155 patients underwent a major liver resection in the simultaneous and classical strategy group, respectively (Table 2). A total of 135 patients underwent a minor liver resection in the simultaneous group and 222 in the classical group. The simultaneous group undergoing minor liver resections had: less often a rectal primary (5 vs. $33 \%, p<0.001)$, less intraoperative blood loss (600 $(300-900)$ vs. $700(350-1250) \mathrm{ml}, p=0.003)$, and shorter total length of stay (11 (7-15) vs. 16 (14-20) days, $p<0.001)$.

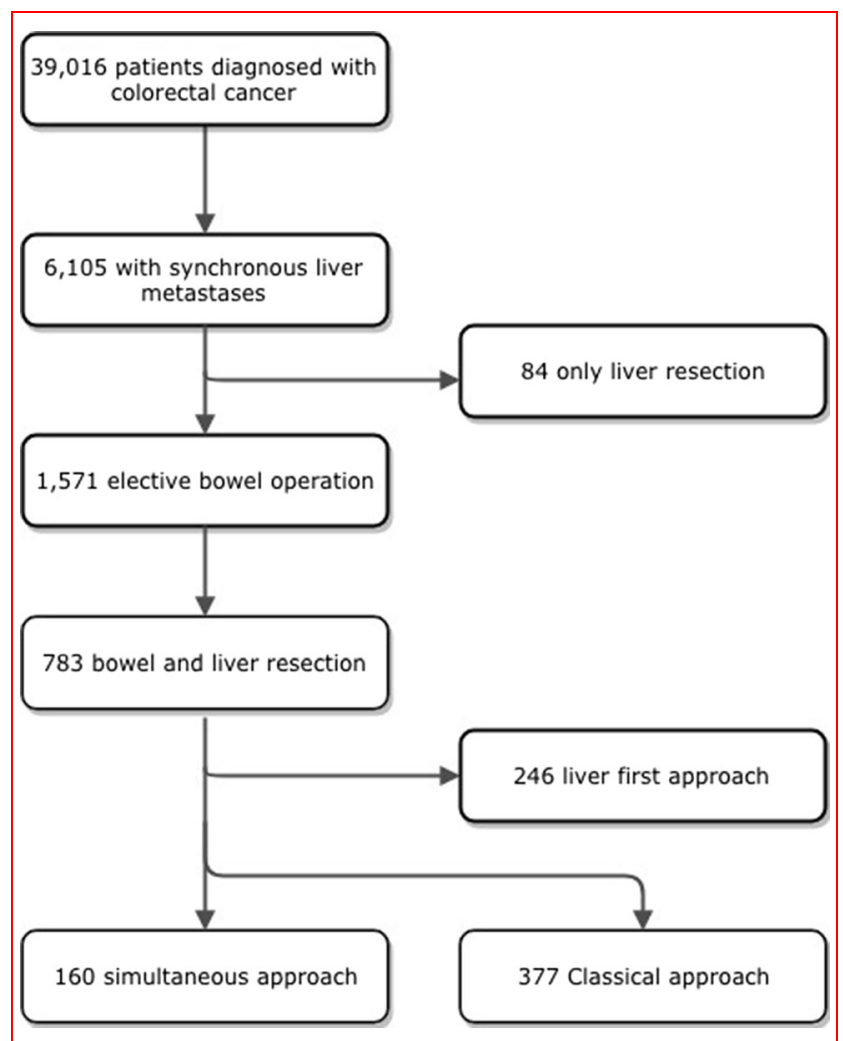

Fig. 1 Flowchart of the patient selection process
For patients experiencing complications, the simultaneous strategy resulted in a shorter total hospital length of stay $(13(10-17)$ vs. $20(15-28)$ days, $p<0.001)$, as compared to the classical strategy. A logistic multivariate odds ratio for complications was significantly increased for simultaneous treatment but decreased for female gender (Table 3).

The median follow-up time was 41 (27-58) months, and overall survival did not differ between groups $(p=0.110)$, with a 5-year survival from diagnosis of $54 \%$ in the classical strategy group and $46 \%$ in the simultaneous strategy group, and median survival was 49 and 58 months, respectively, as shown in Fig. 2. At the end of the study, a total of 231 patients were deceased. For the classical strategy group, the interval between the procedures was 4.7 (2.8-6.1) months. Analyzing the patients undergoing a major liver resection, no difference in overall survival was found between the simultaneous and staged groups $(p=0.198)$.

In Table 4, the results from uni- and multivariate Cox PH models are shown. The multivariate analysis showed higher ASA class, higher liver tumor burden, and T4 primary tumor to be risk factors for decreased overall survival but not simultaneous or staged operation.

The group undergoing colorectal resection only (that is, without subsequent liver resection) was older (72 (64-79) years, $p<0.001)$ and had more frequently: T4 primary tumors $(291(37 \%), p=0.010)$, lymphatic node-positive primaries $(630(82 \%), p<0.001)$, and ASA score of $3-4$ (228 (29\%), $p=0.027)$, compared to the simultaneous group. The primary only group received less often neoadjuvant chemotherapy (59 (7\%), $p<0.001)$ and radiation therapy (83 $(11 \%), p=0.01)$, compared to the simultaneous group. The primary only group had $11 \% 5$-year overall survival and a median survival of 15 months.

\section{Discussion}

The aim of the present study was to compare the simultaneous strategy to the classical strategy for all patients diagnosed with sCRLM, using data from two national quality cancer registries from Sweden. It was found that $16 \%$ of the patients diagnosed with colorectal cancer had sCRLM, which is in line with previous studies [14]. About $50 \%$ of the patients that underwent elective colorectal resections did not undergo liver resections. The reason these patients did not undergo liver resections is unknown, but symptomatic palliative resections probably account for some of the resections. Palliative colorectal resection rates in patients with sCRLM have been reported to be between 16 and 60\% [15-17]. As the data used for the present study do not allow identification of palliative resections, no 
Table 1 Clinical features of patients

\begin{tabular}{|c|c|c|c|}
\hline & Simultaneous strategy & Classical strategy & $p^{*}$ \\
\hline Patients & 160 & 377 & \\
\hline Male gender & $90(56)$ & $234(62)$ & 0.211 \\
\hline Age (years)* & $65(58-72)$ & $66(58-73)$ & 0.396 \\
\hline American Society of Anesthesiologists (3-4) & $32(20)$ & $74(20)$ & $0.906^{\S}$ \\
\hline Body mass index $\left(\mathrm{kg} / \mathrm{m}^{2}\right) *$ & $25(22-28)$ & $25(23-28)$ & $0.434^{\S}$ \\
\hline Preoperative radiotherapy & $29(18)$ & $84(22)$ & 0.300 \\
\hline Neoadjuvant chemotherapy & $101(64)$ & $274(73)$ & 0.029 \\
\hline Localization (rectum) & $35(22)$ & $115(31)$ & 0.046 \\
\hline $\mathrm{T} 4$ primary & $41(26)$ & $85(23)$ & 0.435 \\
\hline Lymphatic node-positive, primary tumors & $105(66)$ & $264(70)$ & 0.411 \\
\hline Number of liver tumors* & $2(1-4)$ & $2(1-4)$ & $1^{\S}$ \\
\hline Liver tumor size $(\mathrm{mm})^{*}$ & $20(12-30)$ & $20(14-35)$ & $0.202^{\S}$ \\
\hline Tumor burden score* & $3.2(2.1-4.5)$ & $3.6(2.2-4.2)$ & $0.500^{\S}$ \\
\hline Portal vein embolization & $0(0)$ & $15(4)$ & 0.008 \\
\hline Major liver surgery & $25(16)$ & $152(41)$ & $<0.001$ \\
\hline Radical liver resection & $145(91)$ & $350(93)$ & 0.370 \\
\hline Total loss of blood $(\mathrm{ml})^{*}$ & $600(250-950)$ & $850(474-1456)$ & $<0.001^{\S}$ \\
\hline Complications, demanding treatment & $84(52)$ & $136(36)$ & $<0.001$ \\
\hline Total length of stay (days)* & $11(8-15)$ & $15(12-20)$ & $<0.001^{\S}$ \\
\hline
\end{tabular}

Percentages are in parentheses unless otherwise indicated: *median (interquartile range). ${ }^{\ddagger}$ Chi-square test, except ${ }^{\S}$ Mann-Whitney $U$ test

Table 2 Clinical features of patients that underwent a major liver resection

\begin{tabular}{|c|c|c|c|}
\hline & Simultaneous strategy & Classical strategy & $p^{*}$ \\
\hline Patients & 25 & 155 & \\
\hline Male gender & $12(48)$ & $98(63)$ & 0.185 \\
\hline Age (years)* & $63(59-68)$ & $65(58-69)$ & $0.820^{\S}$ \\
\hline American Society of Anesthesiologists (3-4) & $5(20)$ & $31(17)$ & 0.576 \\
\hline Body mass index $\left(\mathrm{kg} / \mathrm{m}^{2}\right) *$ & $25(24-26)$ & $25(23-27)$ & $0.828^{\S}$ \\
\hline Preoperative radiotherapy & $3(12)$ & $29(19)$ & 0.576 \\
\hline Neoadjuvant chemotherapy & $21(84)$ & $127(82)$ & 0.770 \\
\hline Localization (rectum) & $6(24)$ & $41(26)$ & 0.878 \\
\hline $\mathrm{T} 4$ primary & $3(12)$ & $39(25)$ & 0.419 \\
\hline Lymphatic node-positive, primary & $20(80)$ & $115(75)$ & 0.802 \\
\hline Number of liver tumors* & $3(2-4)$ & $3(2-4)$ & 0.985 \\
\hline Liver tumor size $(\mathrm{mm})^{*}$ & $31(20-59)$ & $25(15-43)$ & $0.119^{\S}$ \\
\hline Tumor burden score* & $5.7(3.2-7.2)$ & $4.5(3.3-6.4)$ & $0.408^{\S}$ \\
\hline Portal vein embolization & $0(0)$ & $15(10)$ & 0.222 \\
\hline Radical liver resection & $24(96)$ & $143(93)$ & 1 \\
\hline Total loss of blood $(\mathrm{ml})^{*}$ & $1100(500-1600)$ & $1100(630-1800)$ & $0.6393^{\S}$ \\
\hline Complications, demanding treatment & $11(44)$ & $57(37)$ & 0.5109 \\
\hline Total length of stay (days)* & $11(9-15)$ & $17(14-21)$ & $<0.001^{\S}$ \\
\hline
\end{tabular}

Percentages are in parentheses unless otherwise indicated: *median (interquartile range). ${ }^{\ddagger}$ Chi-square test, except ${ }^{\S}$ Mann-Whitney $U$ test 
Table 3 Uni- and multivariate logistic regression for complications needing treatment

\begin{tabular}{|c|c|c|c|c|}
\hline & Univariate analysis & & Multivariate analysis & \\
\hline \multicolumn{5}{|l|}{ Treatment } \\
\hline Classical strategy & Reference & & Reference & \\
\hline Simultaneous strategy & $2.52(1.72-3.69)$ & $<0.001 *$ & $2.23(1.39-3.58)$ & $<0.001 *$ \\
\hline \multicolumn{5}{|l|}{ Age (years) } \\
\hline$<65$ & Reference & & Reference & \\
\hline$\geq 65$ & $0.91(0.64-1.29)$ & 0.579 & $0.86(0.57-1.29)$ & 0.461 \\
\hline \multicolumn{5}{|l|}{ Gender } \\
\hline Male & Reference & & Reference & \\
\hline Female & $0.67(0.46-0.96)$ & $0.03 *$ & $0.65(0.43-0.98)$ & $0.041 *$ \\
\hline \multicolumn{5}{|c|}{ American Society of Anesthesiologists } \\
\hline $1-2$ & Reference & & Reference & \\
\hline $3-4$ & $1.43(0.93-2.21)$ & 0.103 & $1.36(0.84-2.2)$ & 0.212 \\
\hline \multicolumn{5}{|l|}{ Body mass index $\left(\mathrm{kg} / \mathrm{m}^{2}\right)$} \\
\hline$<25$ & Reference & & Reference & \\
\hline$\geq 25$ & $0.94(0.66-1.36)$ & 0.751 & $0.98(0.65-1.46)$ & 0.904 \\
\hline \multicolumn{5}{|l|}{ Tumor localization } \\
\hline Colon primary & Reference & & Reference & \\
\hline Rectal primary & $1.44(0.98-2.12)$ & 0.061 & $0.81(0.37-1.67)$ & 0.573 \\
\hline \multicolumn{5}{|l|}{ Liver resection size } \\
\hline Minor & Reference & & Reference & \\
\hline Major & $0.73(0.5-1.06)$ & 0.103 & $0.8(0.51-1.24)$ & 0.318 \\
\hline \multicolumn{5}{|l|}{ Radiotherapy } \\
\hline No & Reference & & Reference & \\
\hline Yes & $1.93(1.27-2.94)$ & $0.002 *$ & $1.89(0.84-4.45)$ & 0.134 \\
\hline \multicolumn{5}{|l|}{ Bleeding } \\
\hline$<600 \mathrm{ml}$ & Reference & & Reference & \\
\hline$\geq 600 \mathrm{ml}$ & $1.09(0.72-1.63)$ & 0.692 & $1.04(0.66-1.62)$ & 0.863 \\
\hline \multicolumn{5}{|l|}{ Neoadjuvant chemotherapy } \\
\hline No & Reference & & Reference & \\
\hline Yes & $2.11(1.47-3.04)$ & $<0.001 *$ & $1.52(0.95-2.41)$ & 0.080 \\
\hline
\end{tabular}

Data are presented as odds ratios with a $95 \%$ confidence interval in parenthesis. $* p<0.05$

analysis by intention to treat could be made. The reason for not undergoing liver resections could also be that a patient with a curative intention did not finish the planned strategy, i.e., liver and colorectal. It has been shown that about 35\% of patients diagnosed with sCRLM do not finish a planned liver and colorectal resection, regardless of the treatment strategy, mostly due to disease progression [18].

No differences regarding gender, age, ASA score, BMI, T4 primary stage, lymph node-positive primaries, or liver tumor burden score were found between the simultaneous and classical strategy groups. However, rectal cancer and major liver resections were more frequent in the classical strategy group. This indicates that patients are selected for either strategy based on the size of the planned liver surgery and whether they have a rectal or colon primary tumor. In a meta-analysis by Gavriilidis et al., no significant pooled difference was found for gender, age, rectal primary, size, or number of liver tumors or complications, but the simultaneous strategy group had a shorter total length of stay, received less often neoadjuvant therapy, and underwent less often major liver resections [19]

Concerning morbidity, it was not possible to separate major morbidity (Clavien-Dindo grade $\geq 3$ ) from minor morbidity in the present study. Despite the higher complication rate in the simultaneous group, the total length of stay was shorter, perhaps pointing to less clinically significant complications. Increased morbidity after simultaneous resections has also been published [20]. In the present study, no difference in survival could be found between groups, as reported in previous studies [19-21]. 
Fig. 2 Overall survival from diagnosis for resected patients with synchronous liver metastases, $p=0.110$ (log-rank test)
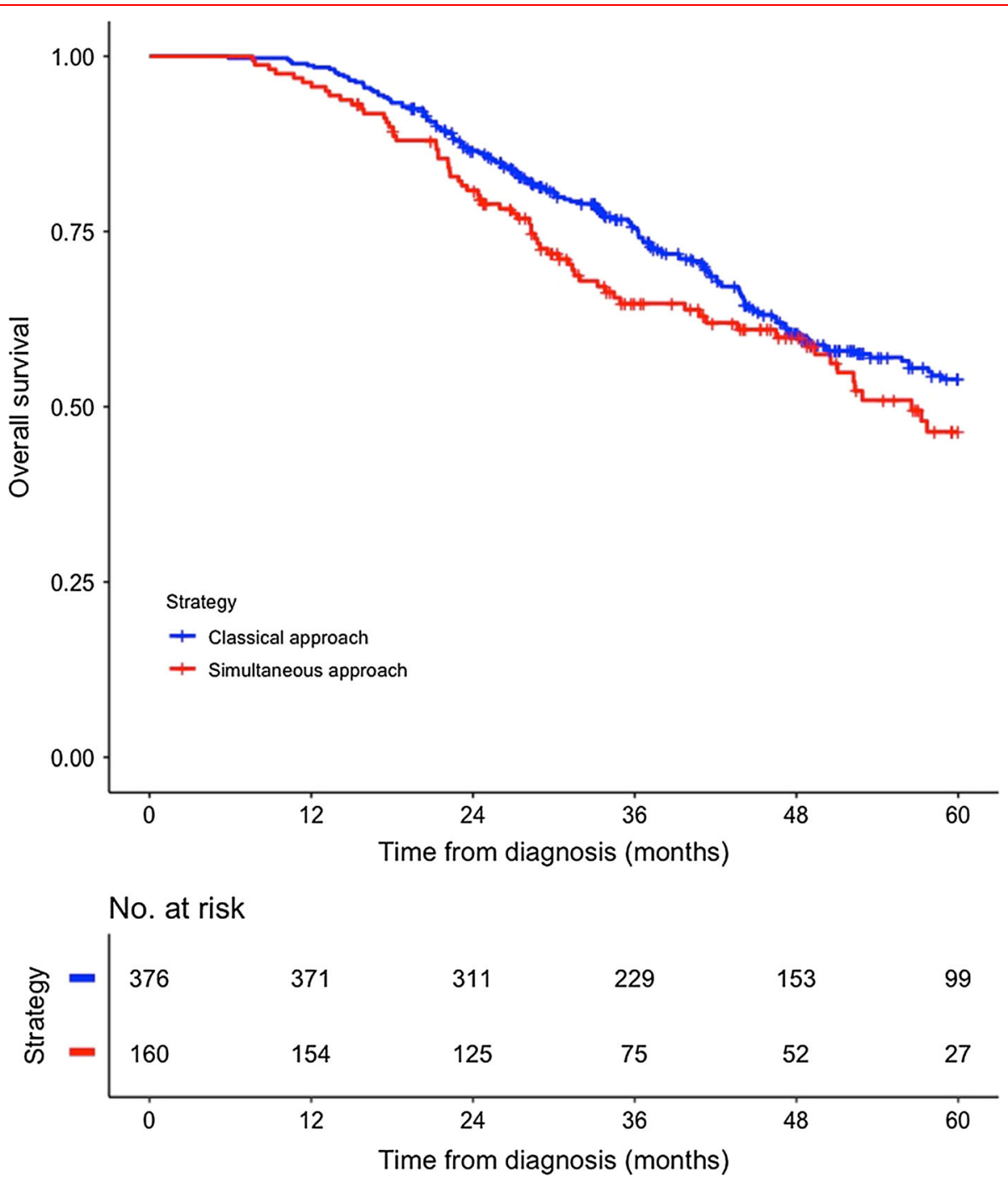

If a simultaneous procedure significantly shortens the hospital stay from 15 (12-20) to 11 (8-15) days and a cost of a hospital bed in Sweden is USD 914 [22], the cost per patient could be reduced from USD 13,710 $(10,968-18,280)$ to USD 10054 (7312-13,710).

The use of laparoscopy was rare during the study period, with only 18 patients $(5 \%)$ in the classical strategy group and 4 patients $(3 \%)$ in the simultaneous strategy group who underwent laparoscopic liver procedures. Data on the use of laparoscopy for resecting colon and rectal cancer in the classical strategy were missing in the present study. Registry data on colon resections for cancer during 2007-2011 in Sweden showed that $6 \%$ of resections were performed laparoscopically [11]. Comparing the groups of patients that underwent major liver resections (simultaneous vs. classical strategy), a significant difference was found for a shorter total length of hospital stay only. No significant 5-year survival difference was found, in line with previously published studies [21, 23-26]. The sample size was, however, small in the simultaneous major liver resection group $(N=25)$, making it difficult to make a definite conclusion on the result.

Cox PH analysis showed that a more advanced colorectal cancer and liver tumor disease, and higher comorbidity negatively affected survival in univariate analysis. On multivariate analysis, an increased tumor burden score, T4 primary stage, and higher comorbidity were related to worse survival, shown in Table 3 . These factors have previously been linked to survival [13].

No randomized controlled trial evidence is available to support the use of any strategy for patients with sCRLM. All published studies, therefore, have an intrinsic selection and referral biases [27], as is the case with this study. No multivariate analysis models, such as propensity score matching, retrospective matching, or other regression models, can ever replace randomization. A propensity 
Table 4 Cox proportional hazards analysis for overall survival

\begin{tabular}{|c|c|c|c|c|}
\hline & Univariate $\mathrm{HR}$ & & Multivariate HR & \\
\hline \multicolumn{5}{|l|}{ Treatment } \\
\hline Classical strategy & Reference & & Reference & \\
\hline Simultaneous strategy & $0.79(0.59-1.05)$ & 0.107 & $0.83(0.6-1.14)$ & 0.243 \\
\hline \multicolumn{5}{|l|}{ Age (in years) } \\
\hline$<60$ & Reference & & Reference & \\
\hline$\geq 60-70$ & $0.78(0.56-1.09)$ & 0.140 & $0.78(0.54-1.13)$ & 0.189 \\
\hline$\geq 70$ & $1.15(0.83-1.6)$ & 0.407 & $1.18(0.81-1.7)$ & 0.392 \\
\hline \multicolumn{5}{|l|}{ Gender } \\
\hline Male & Reference & & Reference & \\
\hline Female & $0.83(0.62-1.1)$ & 0.199 & $0.9(0.66-1.22)$ & 0.495 \\
\hline \multicolumn{5}{|c|}{ Lymphatic node primary tumor } \\
\hline Negative & Reference & & Reference & \\
\hline Positive & $1.55(1.13-2.12)$ & $0.007^{*}$ & $1.26(0.9-1.75)$ & 0.182 \\
\hline \multicolumn{5}{|l|}{ pT4 primary tumor } \\
\hline No & Reference & & Reference & \\
\hline Yes & $1.92(1.43-2.57)$ & $<0.001^{*}$ & $1.84(1.34-2.54)$ & $<0.001^{*}$ \\
\hline \multicolumn{5}{|l|}{ Primary tumor localization } \\
\hline Colon & Reference & & & \\
\hline Rectum & $0.98(0.73-1.31)$ & 0.877 & & \\
\hline \multicolumn{5}{|l|}{ Liver resection size } \\
\hline Minor & Reference & & & \\
\hline Major & $1.1(0.83-1.46)$ & 0.494 & & \\
\hline \multicolumn{5}{|l|}{ Tumor burden score } \\
\hline$<3$ & Reference & & Reference & \\
\hline$\geq 3-9$ & $1.67(1.21-2.29)$ & $0.002 *$ & $1.73(1.24-2.41)$ & $0.001 *$ \\
\hline$\geq 9$ & $2.99(1.86-4.81)$ & $<0.001^{*}$ & $3.04(1.83-5.04)$ & $<0.001^{*}$ \\
\hline \multicolumn{5}{|l|}{ Liver tumor numbers } \\
\hline$<3$ & Reference & & & \\
\hline$\geq 3$ & $1.53(1.16-2.02)$ & $0.003 *$ & & \\
\hline \multicolumn{5}{|l|}{ Liver tumor size $(\mathrm{cm})$} \\
\hline$<5$ & Reference & & & \\
\hline$\geq 5$ & $1.92(1.33-2.77)$ & $<0.001 *$ & & \\
\hline \multicolumn{5}{|c|}{ American Society of Anesthesiologists } \\
\hline $1-2$ & Reference & & Reference & \\
\hline $3-4$ & $1.47(1.07-2.02)$ & $0.019 *$ & $1.52(1.09-2.13)$ & $0.014 *$ \\
\hline \multicolumn{5}{|l|}{ Body mass index $\left(\mathrm{kg} / \mathrm{m}^{2}\right)$} \\
\hline$<25$ & Reference & & & \\
\hline$\geq 25-35$ & $1.09(0.82-1.46)$ & 0.545 & & \\
\hline$\geq 35$ & $1.39(0.61-3.18)$ & 0.436 & & \\
\hline
\end{tabular}

Data are presented as hazard ratios (HR) with a $95 \%$ confidence interval (CI) in parenthesis. ${ }^{*} p<0.05$

score matching has gained increased popularity in recent years, with an often unclear matching process. A statistical regression model is often more transparent and can even be more useful and comprehensive when detecting differences in treatment effect $[28,29]$.
One of the weaknesses of the present study is that the used registries do not allow calculation of recurrence-free survival, nor was it possible to analyze the data according to intention to treat. Another shortcoming of the study is that no data on adjuvant chemotherapy were included. The usage rates of adjuvant chemotherapy have previously not 
shown to differ between strategies [22]. The strength of this study is that it is based on a national population with a prospective registration.

In conclusion, the present study has shown that patients chosen for simultaneous liver and primary resection had a shorter total length of hospital stay, similar overall survival but can possibly have more complications compared to patients allocated to a classical strategy.

Acknowledgements Open access funding provided by Karolinska Institute.

Funding This research did not receive any specific grant from funding agencies in the public, commercial, or not-for-profit sectors.

\section{Compliance with ethical standards}

Conflict of interest The authors declare that there is no conflict of interest.

Ethics approval It is approved by the regional ethics committee, Lund, Sweden.

Open Access This article is licensed under a Creative Commons Attribution 4.0 International License, which permits use, sharing, adaptation, distribution and reproduction in any medium or format, as long as you give appropriate credit to the original author(s) and the source, provide a link to the Creative Commons licence, and indicate if changes were made. The images or other third party material in this article are included in the article's Creative Commons licence, unless indicated otherwise in a credit line to the material. If material is not included in the article's Creative Commons licence and your intended use is not permitted by statutory regulation or exceeds the permitted use, you will need to obtain permission directly from the copyright holder. To view a copy of this licence, visit http://creativecommons. org/licenses/by/4.0/.

\section{References}

1. Parkin DM, Bray F, Ferlay J, Pisani P (2002) Global cancer statistics, 2002. CA Cancer J Clin 55:74-108. https://doi.org/10. 3322/canjclin.55.2.74

2. Ferlay J, Soerjomataram I, Dikshit R et al (2015) Cancer incidence and mortality worldwide: sources, methods and major patterns in GLOBOCAN 2012. Int J Cancer 136:E359-E386. https://doi.org/10.1002/ijc. 29210

3. Leporrier J, Maurel J, Chiche L et al (2006) A population-based study of the incidence, management and prognosis of hepatic metastases from colorectal cancer. Br J Surg 93:465-474. https:// doi.org/10.1002/bjs.5278

4. Manfredi S, Lepage C, Hatem C et al (2006) Epidemiology and management of liver metastases from colorectal cancer. Ann Surg 244:254-259. https://doi.org/10.1097/01.sla.0000217629.94941. cf

5. Riihimäki M, Hemminki A, Sundquist J et al (2016) Patterns of metastasis in colon and rectal cancer. Sci Rep 6:29765. https:// doi.org/10.1038/srep29765

6. Mentha G, Majno PE, Andres A et al (2006) Neoadjuvant chemotherapy and resection of advanced synchronous liver metastases before treatment of the colorectal primary. Br J Surg 93:872-878. https://doi.org/10.1002/bjs.5346

7. Baltatzis M, Chan AKC, Jegatheeswaran S et al (2016) Colorectal cancer with synchronous hepatic metastases: systematic review of reports comparing synchronous surgery with sequential bowelfirst or liver-first approaches. Eur J Surg Oncol 42:159-165. https://doi.org/10.1016/j.ejso.2015.11.002

8. Jegatheeswaran S, Mason JM, Hancock HC, Siriwardena AK (2013) The liver-first approach to the management of colorectal cancer with synchronous hepatic metastases: a systematic review. JAMA Surg 148:385-391. https://doi.org/10.1001/jamasurg. 2013.1216

9. Kelly ME, Spolverato G, Le GN et al (2015) Synchronous colorectal liver metastasis: a network meta-analysis review comparing classical, combined, and liver-first surgical strategies. J Surg Oncol 111:341-351. https://doi.org/10.1002/jso.23819

10. Welsh FKS, Chandrakumaran K, John TG et al (2016) Propensity score-matched outcomes analysis of the liver-first approach for synchronous colorectal liver metastases. Br J Surg 103:600-606. https://doi.org/10.1002/bjs.10099

11. Kodeda K, Nathanaelsson L, Jung B et al (2013) Populationbased data from the Swedish Colon Cancer Registry. Br J Surg 100:1100-1107. https://doi.org/10.1002/bjs.9166

12. Årsrapport nationellt kvalitetsregister 2017 (2018) Cancer i lever och gallvägar. https://www.cancercentrum.se/globalassets/cancer diagnoser/lever-och-galla/kvalitetsregister/sweliv_rapport_2018. pdf. Accessed 18 Nov 2019

13. Sasaki K, Morioka D, Conci S et al (2016) The tumor burden score: a new, "metro-ticket" prognostic tool for colorectal liver metastases based on tumor size and number of tumors. Ann Surg 267:132-141. https://doi.org/10.1097/SLA.0000000000002064

14. Noren A, Eriksson HG, Olsson LI (2016) Selection for surgery and survival of synchronous colorectal liver metastases; a nationwide study. Eur J Cancer 53:105-114. https://doi.org/10. 1016/j.ejca.2015.10.055

15. Yun J-A, Huh JW, Park YA et al (2014) The role of palliative resection for asymptomatic primary tumor in patients with unresectable stage IV colorectal cancer. Dis Colon Rectum 57:1049-1058. https://doi.org/10.1097/DCR.0000000000000193

16. Gulack BC, Nussbaum DP, Keenan JE et al (2016) Surgical resection of the primary tumor in stage IV colorectal cancer without metastasectomy is associated with improved overall survival compared to chemotherapy/radiation therapy alone. Dis Colon Rectum 59:299-305. https://doi.org/10.1097/DCR. 0000000000000546

17. Tarantino I, Warschkow R, Worni M et al (2015) Prognostic relevance of palliative primary tumor removal in 37,793 metastatic colorectal cancer patients. Ann Surg 262:112-120. https:// doi.org/10.1097/SLA.0000000000000860

18. Sturesson C, Valdimarsson VT, Blomstrand E et al (2017) Liverfirst strategy for synchronous colorectal liver metastases-an intention-to-treat analysis. HPB 19:1-7. https://doi.org/10.1016/j. hpb.2016.10.005

19. Gavriilidis P, Sutcliffe RP, Hodson J et al (2018) Simultaneous versus delayed hepatectomy for synchronous colorectal liver metastases: a systematic review and meta-analysis. HPB 20:11-19

20. Reddy SK, Pawlik TM, Zorzi D et al (2007) Simultaneous resections of colorectal cancer and synchronous liver metastases: a multi-institutional analysis. Ann Surg Oncol 14:3481-3491. https://doi.org/10.1245/s10434-007-9522-5

21. Slesser AAP, Simillis C, Goldin R et al (2013) A meta-analysis comparing simultaneous versus delayed resections in patients with synchronous colorectal liver metastases. Surg Oncol 22:36-47 
22. WHO. Country-specific unit costs. https://www.who.int/choice/ country/country_specific/en/. Accessed 18 Nov 2019

23. Silberhumer GR, Paty PB, Temple LK et al (2015) Simultaneous resection for rectal cancer with synchronous liver metastasis is a safe procedure. Am J Surg 209:935-942. https://doi.org/10.1016/ j.amjsurg.2014.09.024

24. Muangkaew P, Cho JY, Han H-S et al (2016) Outcomes of simultaneous major liver resection and colorectal surgery for colorectal liver metastases. J Gastrointest Surg 20:554-563. https://doi.org/10.1007/s11605-015-2979-9

25. Capussotti L, Ferrero A, Viganò L et al (2006) Major liver resections synchronous with colorectal surgery. Ann Surg Oncol 14:195-201. https://doi.org/10.1245/s10434-006-9055-3

26. Fukami Y, Kaneoka Y, Maeda A et al (2016) Simultaneous resection for colorectal cancer and synchronous liver metastases.
Surg Today 46:176-182. https://doi.org/10.1007/s00595-0151188-1

27. Morris E, Treasure T (2017) If a picture is worth a thousand words, take a good look at the picture: Survival after liver metastasectomy for colorectal cancer. Cancer Epidemiol 49:152-155. https://doi.org/10.1016/j.canep.2017.06.009

28. Biondi-Zoccai G, Romagnoli E, Agostoni P et al (2011) Are propensity scores really superior to standard multivariable analysis? Contemp Clin Trials 32:731-740

29. Brazauskas R, Logan BR (2016) Observational studies: matching or regression? Biol Blood Marrow Transplant 22:557-563. https://doi.org/10.1016/j.bbmt.2015.12.005

Publisher's Note Springer Nature remains neutral with regard to jurisdictional claims in published maps and institutional affiliations. 